\title{
¿Quién lleva la batuta en temas de movilidad urbana en Costa Rica? 20 años de lecciones del hundimiento de los Planes de Movilidad
}

\author{
Verena Arauz Schulze-Boysen \\ Apartado 8-4190, 1000 San José; verena.arauz@googlemail.com \\ Recibido 02-IX-2018 • Corregido 16-XII-2018 • Aceptado 14-I-2019
}

\begin{abstract}
Who leads de way towards a better urban mobility in Costa Rica? Lessons learnt from 20 years of stagnation. In Costa Rica, the transport sector is the main contributor of greenhouse gases. Here, I present a critical analysis of Costa Rica's national policies and governance associated with urban mobility initiatives in the Great Metropolitan Area within a climate change context.
\end{abstract}

Key words: Climate change, mitigation, greenhouse gases, sustainable transportation, air quality.
RESUMEN: En Costa Rica, el sector transporte es el principal contribuyente de los gases de efecto invernadero. Aquí se presenta un análisis crítico de las políticas nacionales y gobernanza asociadas a las iniciativas de movilidad urbana en la Gran Área Metropolitana de Costa Rica en un contexto del cambio climático.

Palabras Clave: Cambio climático, mitigación, gases de efecto invernadero, transporte sostenible, calidad del aire.
En Costa Rica, I Plan Regional Urbano de la Gran Área Metropolitana 2008-2030, mejor conocido como el PRUGAM - está en el vocabulario de muchos funcionarios públicos, académicos y consultores que trabajan en el área de urbanismo y transporte en San José. Se recordará como un esfuerzo conjunto y financiado por la Unión Europea y coordinado por el actual Viceministro de Transportes Eduardo Brenes, para impulsar ciudades para la gente. Si bien, se generó un diagnóstico muy exhaustivo y las bases siguen sirviendo para trabajos más actuales, no pasó de ser un esfuerzo - porque diez años después, la GAM se ahoga en presas peores que nunca.

EI PRUGAM no se quedó solo en esta condición, ya le antecedía el Plan de Sectorización de Transporte Público, que cumple veinte años de ser elaborado y no ha dado frutos. También le siguió el POTGAM, el Plan GAM y recientemente el Plan Integral de Movilidad Urbana Sostenible PIMUS. Muchos de estos planes no divergen tanto entre ellos. Un denominador común que tienen, es que todos recalcan la institucionalidad débil del país en materia de movilidad urbana.

El PIMUS, el más "nuevo" de los planes, tenía una variable nueva: al haber sido financiado por medio del Fondo
Global para el Ambiente (GEF - por sus siglas en inglés), tenía una componente fuerte de mitigación de Gases de Efecto Invernadero. Si bien en el país se ha quedado estancado en el transporte público, en políticas de cambio climático si ha dado grandes saltos.

En vista de que el transporte es causante del $38 \%$ de los Gases de Efecto Invernadero (GEI) en el país, la consecuencia lógica es, que muchos de los esfuerzos de mitigación se dieran en justo esa área. Se vuelvan a atraer fondos de cooperación (que se habían dejado de percibir por la Ayuda Oficial al Desarrollo, y la Dirección de Cambio Climático del Ministerio de Ambiente y Energía (MINAE)asume un rol de coordinación entre los múltiples actores en movilidad urbana: Ministerio de Obras Públicas y Transportes (MOPT), Ministerio de Vivienda y Asentamientos Humanos (MIVAH), Municipalidades, Concejo de Transporte Público (CTP), Instituto Costarricense de Ferrocarriles (INCOFER), para mencionar algunos. Y en la buena teoría, se tendrían documentos consensuados, ya que el MINAE en esta materia conserva un carácter de facilitador. Pero ¿está bien eso, siendo el MOPT la institución a la que más le tocaría implementar cambios? Y es aquí donde empiezan las peleas entre las 
instituciones. A los talleres siempre asisten todos, pero cuando se trata de implementar, de buscar presupuesto, de pronto ya no hay tanto consenso sobre los productos generados a raíz de una consultoría.

$Y$ esto es lo que ha frenado - una vez más - la oficialización de otro Plan de Movilidad, uno más moderno y de acuerdo con los patrones de desplazamiento de los habitantes del Área Metropolitana de San José. En este punto es irrelevante debatir sobre cuál es la entidad que debería llevar la batuta. Si bien, el impacto sobre la variable climática es significante y está muy en el discurso de la "Descarbonización de la Economía" del actual gobierno, está lejos de ser la más relevante.

El caos vial le está pasando la factura a la economía y competitividad del país y naturalmente también a las personas más pobres. Estas pueden pagar hasta un 30\% en pasajes de autobús - no porque las tarifas individuales sean muy altas - sino que por que la ciudad está tan desconectada, en algunos casos se deben tomar hasta tres buses para llegar al destino final.

El discurso climático es políticamente atractivo y puede atraer fondos de cooperación a nivel internacional, pero no hay que perder de vista que son el MOPT, el Consejo de Transporte Público y INCOFER de forma conjunta, los que pueden ejecutar los proyectos sustanciales de mejora de la movilidad urbana.
Idealmente hay que aspirar una autoridad metropolitana de transporte - como la hay en la mayoría de ciudades grandes en el mundo - y este proceso político es uno que debe llevarse en paralelo a los pequeños cambios que se quieren dar por ejemplo con las rutas de autobús. Mientras tanto, los roles están claros. Transporte público es competencia del MOPT. El MINAE por su parte, puede también hacer las tareas que le competen directamente, por ejemplo limitar la importación de vehículos usados o muy contaminantes, monitorear mejor en aduanas, que en efecto se cumplan estos lineamientos, imponer estándares de emisión, ya que el transporte también deja su huella en la Calidad del Aire, implementar políticas de chatarrización de vehículos que hayan cumplido su vida útil, crear incentivos y facilitar la transición hacia vehículos eléctricos entre muchos otros. En muchas ciudades del mundo, la limitación de la entrada de vehículos más contaminantes, también ha sido impulsada por la afectación a la salud humana. El Ministerio de Salud de Costa Rica, sin embargo, no ha asumido su responsabilidad en este tema tampoco.

Finalmente, lo que cada ciudadano quiere, es vivir en una ciudad donde uno se pueda movilizar de forma rápida y segura, en cualquier medio de transporte y respirando aire limpio. Si las instituciones hacen lo que les toca de forma eficiente - mientras que se trabaja en una mejora institucional - se podría llegar mucho antes a esa meta. 